\title{
Oral Clinical Factors Affecting Self-Perception of Oral Health
}

\author{
Dajana Nogo-Živanović, Ljiljana Kulić, Aleksandra Žuža, Brankica Davidović, Igor Radović \\ University of East Sarajevo, Faculty of Medicine, Department of Restorative Dentistry and Endodontics, Foča, \\ Republika Srpska, Bosnia and Herzegovina
}

\begin{abstract}
SUMMARY
Introduction Self- assessment of oral health is simple, non-invasive and cost-effective method of collecting data that takes into account psychosocial aspects of oral health. The aim of this study was to investigate the effect of clinical factors on the self-perception of oral health in middle-aged patients in Republika Srpska (Bosnia and Herzegovina).

Material and Methods The study included 126 subjects of both genders (34.1\% male and 65.9\% female) aged 24-54 years. Data were collected through questionnaires and clinical examination. Anonymous questionnaire contained questions related to socio-demographic characteristics of respondents. Clinical examination included teeth condition and the presence of prosthetic restorations. Self-perception of oral health was determined by one question.

Results Bivariate analysis indicated significant effect of carious $(p<0.001)$, missing $(p<0.001)$ and filled teeth $(p=0.022)$ but not the prosthetic status on self-perception of oral health. Correlation between the number of carious and missing teeth with self-perception of oral health was significant in regression analysis.

Conclusion The number of carious and missing teeth had significant impact on self-assessment of oral health in studied population. Knowledge of effects of oral clinical variables on self-perception of oral health is very important to obtain clearer insight into the association between objectively and subjectively assessed oral health.
\end{abstract}

Keywords: evaluation of oral health; caries; socioeconomic factors

\section{INTRODUCTION}

Clinical indicators are most commonly used for the evaluation of oral health in clinical and epidemiological research [1]. This way of oral health assessment has many advantages, however, disadvantages include no consideration of psychosocial aspects and individual perception of oral health [2]. Individual assessment of oral health can provide useful information [3]. This method is easy to use and economically more acceptable than clinical trials [4, $5,6]$. Self-perception of oral health is based usually on one question only [6].

Many studies have found association between the selfperception of oral health determined on one question and number of clinical indicators of oral health [4, 7-10]. Persons with larger number of carious and extracted teeth usually assess their oral health as poor $[5,7,10]$, while those with large number of restored teeth assess their oral health as good $[5,7]$. Poor oral health is associated with high DMFT index, malocclusion, toothache and TMJ pain, prosthetic status and need for dental treatment $[5,7,11,12]$.

One study done in Serbia showed that nearly half of adult population (45.5\%) assessed their teeth and mouth condition as good or very good [13]. It has also been shown that the assessment of oral health is related to total household income, education, gender and geographical region [13].

The aim of this study was to investigate the effect of clinical factors on the assessment of oral health in middle-aged patients in Republika Srpska (Bosnia and Herzegovina).

\section{MATERIAL AND METHODS}

Cross-sectional study was conducted at the Department of Restorative Dentistry and Endodontics, Faculty of Medicine Foča, University of East Sarajevo, Republika Srpska (B\&H), from January to July 2013. The sample consisted of 126 respondents of both genders (34.1\% male and 65.9\% female) aged 24-54 years (mean age \pm standard deviation: $32.36 \pm 5.93$ years). The target population was selected randomly from patients of the Department of Restorative Dentistry and Endodontics, Faculty of Medicine, Foča. After explanation about objectives and expected outcomes of the research, all subjects signed informed consent to participate in research.

Data were collected through questionnaires and clinical examination. The anonymous questionnaire contained questions related to socio-demographic characteristics: age, gender, level of education (completed elementary school, completed high school, completed college, university and more), employment (employed full-time, employed part-time, unemployed), the total monthly income of all household members ( $<$ than one average salary in RS, 1-2 average salaries in RS, 2-3 average salaries in RS, $>4$ average salaries in RS (in the period when survey was conducted)), smoking habits in the past year (yes, no) and the time since last visit to the dentist (visit within last 6 months, 6-12 months, between 1-2 years and more than 2 years). The studied variables were dichotomized for the purpose of statistical analysis. The level of education was classified into two categories: elementary and/or high 
school and completed college and more; employment was classified as: employed (full-time, part-time) and unemployed; the total income of all household members: up to two average salaries in RS $(<$ than one average salary in RS, 1-2 average salaries in RS) and income higher than two average salaries (2-3 average salaries in RS, $>4$ average salaries in RS). Dental visit in the last 12 months was also dichotomized to: visit within 12 months (visit in the last 6 and between 6-12 months) and visit more than 12 months ago (1-2 year, or more than 2 years).

Self-perception of oral health was based on one question: "How would you assess the health of your teeth?" Offered answers were: "excellent","'very good","good", "average", "bad" and "poor". Because regression analysis was used, variables were dichotomized to the following: "excellent","very good", "good" and "average" were combined into one category (good), and "bad" and "very poor" to another category (poor).

Clinical examination included the evaluation of teeth condition and presence of prosthetic restorations. It was performed by trained dentists at the Department of Restorative Dentistry and Endodontics, Faculty of Medicine in Foča with the use of artificial light, dental mirror and probe according to standards and criteria of the World Health Organization [14]. The prevalence of caries was determined by DMFT index and its components (D - decayed, M - missing, F - filled tooth). Intraexaminer repeatability was measured through coefficient kappa and it was 0.85 . The analysis included third molars, and all surfaces of teeth. The evaluation of prosthetic status of upper and lower jaw was based on the presence or absence of any kind of dentures. The respondents were classified into two groups: respondents who had at least one prosthetic restoration (partial and/or complete denture and/or fixed work) and those who did not have any prosthetic restoration.

\section{Statistical analysis}

Statistical analysis was done using SPSS, version 19.0 (IBM SPSS Statistics for Windows, Armonk, NY: IBM Corp., USA) for Windows. Data were presented as mean values and standard deviations (SD) for numerical and frequency for attributive characteristics. Differences in the self-assessment of oral health, depending on the examined variables in bivariate analysis were calculated using t-test for two independent samples and $\chi^{2}$-test. Using logistical regression the association of oral clinical variables and self-assessment of oral health was analyzed. Oral health assessed as good was chosen as reference category. Values of $\mathrm{p}<0.05$ were considered statistically significant in all analyzes.

\section{RESULTS}

Socio-demographic characteristics of respondents and their habits are shown in Table 1. Bivariate analysis

Table 1. Distribution of socio-economic and behavioral parameters depending on self-perception of oral health Tabela 1. Raspodela socioekonomskih parametara i navika ponašanja u zavisnosti od samoprocene oralnog zdravlja

\begin{tabular}{|c|c|c|c|c|}
\hline \multirow{2}{*}{\multicolumn{2}{|c|}{$\begin{array}{l}\text { Parameter } \\
\text { Parametar }\end{array}$}} & \multicolumn{2}{|c|}{$\begin{array}{l}\text { Oral health perception (\%) } \\
\text { Procena oralnog zdravlja (\%) }\end{array}$} & \multirow[b]{2}{*}{$\mathrm{p}$} \\
\hline & & $\begin{array}{l}\text { Good } \\
\text { Dobro }\end{array}$ & $\begin{array}{l}\text { Poor } \\
\text { Loše }\end{array}$ & \\
\hline \multicolumn{2}{|l|}{$\begin{array}{l}\text { Age (years) } \\
\text { Starost (godine) }\end{array}$} & $31.13 \pm 4.90^{*}$ & $33.59 \pm 6.62 *$ & 0.019 \\
\hline \multirow{2}{*}{$\begin{array}{l}\text { Gender } \\
\text { Pol }\end{array}$} & $\begin{array}{l}\text { Male } \\
\text { Muški }\end{array}$ & 46.5 & 53.5 & \multirow{2}{*}{0.707} \\
\hline & $\begin{array}{l}\text { Female } \\
\text { Ženski }\end{array}$ & 51.8 & 48.2 & \\
\hline \multirow{2}{*}{$\begin{array}{l}\text { Level of education } \\
\text { Stepen obrazovanja }\end{array}$} & $\begin{array}{l}\text { High school, elementary school } \\
\text { Srednja stručna sprema, osnovna škola }\end{array}$ & 30.6 & 69.4 & \multirow{2}{*}{$<0.000$} \\
\hline & $\begin{array}{l}\text { College, university degree } \\
\text { Viša škola, visoka stručna sprema }\end{array}$ & 68.8 & 31.2 & \\
\hline \multirow{2}{*}{$\begin{array}{l}\text { Employment } \\
\text { Zaposlenje }\end{array}$} & $\begin{array}{l}\text { Employed } \\
\text { Zaposlen }\end{array}$ & 58.5 & 41.5 & \multirow{2}{*}{0.075} \\
\hline & $\begin{array}{l}\text { Unemployed } \\
\text { Nezaposlen }\end{array}$ & 41.0 & 59.0 & \\
\hline \multirow{2}{*}{$\begin{array}{l}\text { Total household income } \\
\text { Ukupan prihod domaćinstva }\end{array}$} & $\begin{array}{l}\text { Less than two average salaries } \\
\text { Manje od dve prosečne plate }\end{array}$ & 40.7 & 59.3 & \multirow{2}{*}{0.385} \\
\hline & $\begin{array}{l}\text { More than two average salaries } \\
\text { Više od dve prosečne plate }\end{array}$ & 52.5 & 47.5 & \\
\hline \multirow{2}{*}{$\begin{array}{l}\text { Smoking } \\
\text { Pušenje }\end{array}$} & $\begin{array}{l}\text { Yes } \\
\mathrm{Da}\end{array}$ & 23.9 & 76.1 & \multirow{2}{*}{$<0.0001$} \\
\hline & $\begin{array}{l}\text { No } \\
\text { Ne }\end{array}$ & 65.0 & 35.0 & \\
\hline \multirow{2}{*}{$\begin{array}{l}\text { Last visit to dentist } \\
\text { Poslednja poseta stomatologu }\end{array}$} & $\begin{array}{l}\text { Less than } 12 \text { months } \\
\text { Manje od } 12 \text { meseci }\end{array}$ & 54.0 & 46.0 & \multirow{2}{*}{0.123} \\
\hline & $\begin{array}{l}\text { More than } 12 \text { months } \\
\text { Više od } 12 \text { meseci }\end{array}$ & 34.6 & 65.4 & \\
\hline
\end{tabular}

*Values are presented as mean value \pm standard deviation

*Vrednosti su prikazane kao srednja vrednost sa standardnom devijacijom. 
Table 2. Distribution of oral clinical variables depending on the self-perception of oral health

Tabela 2. Raspodela oralnih kliničkih varijabli u zavisnosti od samoprocene oralnog zdravlja

\begin{tabular}{|c|c|c|c|c|}
\hline \multirow{2}{*}{\multicolumn{2}{|c|}{$\begin{array}{l}\text { Variable } \\
\text { Varijabla }\end{array}$}} & \multicolumn{2}{|c|}{$\begin{array}{l}\text { Oral health assessment } \\
\text { Procena oralnog zdravlja }\end{array}$} & \multirow{2}{*}{$\mathrm{p}$} \\
\hline & & $\begin{array}{l}\text { Good } \\
\text { Dobro }\end{array}$ & $\begin{array}{l}\text { Poor } \\
\text { Loše }\end{array}$ & \\
\hline \multicolumn{2}{|l|}{$\begin{array}{l}\text { Number of carious teeth } \\
\text { Broj zuba sa karijesom }\end{array}$} & $0.98 \pm 1.661$ & $3.19 \pm 3063$ & 0.000 \\
\hline \multicolumn{2}{|c|}{$\begin{array}{l}\text { Number of extracted teeth } \\
\text { Broj ekstrahovanih zuba }\end{array}$} & $2.92 \pm 2.484$ & $7.27 \pm 4.378$ & 0.000 \\
\hline \multicolumn{2}{|l|}{$\begin{array}{l}\text { Number of filled teeth } \\
\text { Broj plombiranih zuba }\end{array}$} & $11.37 \pm 4.356$ & $9.67 \pm 3.852$ & 0.022 \\
\hline \multirow{2}{*}{$\begin{array}{l}\text { Prosthetic restoration } \\
\text { Protetička nadoknada }\end{array}$} & $\begin{array}{l}\text { Yes } \\
\text { Da }\end{array}$ & $40.7 \%$ & $59.3 \%$ & \multirow{2}{*}{0.295} \\
\hline & $\begin{array}{l}\mathrm{No} \\
\mathrm{Ne}\end{array}$ & $54.8 \%$ & $45.2 \%$ & \\
\hline
\end{tabular}

showed that age $(\mathrm{p}=0.019)$, educational level $(\mathrm{p}<0.0001)$ and smoking $(\mathrm{p} \leq 0.0001)$ are socio-demographic factors and habits that are associated with oral health perception (Table 1). Of the tested oral clinical variables, the number of carious, missing and filled teeth, but not prosthetic status, were significantly different in respondents who assessed their oral health as good and those who assessed their oral health as poor (Table 2).

After logistic regression analysis, variables that were found associated with oral health evaluation were number of carious $(p \leq 0.0001)$ and missing $(p \leq 0.0001)$ teeth. People with lower number of carious and missing teeth assessed their oral health as good (Table 3). The association between dental caries and missing teeth with selfperception of oral health remained significant even after adjusting for gender, age, educational level and smoking habit.

\section{DISCUSSION}

Our study shows association between the number of carious and missing teeth and oral health perception.

There is indirect association between sociodemographic factors such as environmental factors, psychosocial factors, lifestyle and accessibility of dental care and evaluation of oral health [15]. Sociodemographic factors may also directly or indirectly affect individual's percep- tion of oral health $[15,16]$. Total household income have major impact on the assessment of oral health [17] and respondents with lower income more often evaluate their oral health as poor $[17,18]$. Also, age, lower socioeconomic status and lower level of education are associated with oral health assessment as poor [19]. Similar findings were obtained in the current study. Of the tested sociodemographic characteristics significant relationship was observed between the assessment of oral health and age, educational level and smoking. Smoking may have an impact on the assessment of oral health [20] due to its effect on development of caries [21].

The analysis of individual components of DMFT index in the current study revealed significant difference in the number of carious, missing and filled teeth between those respondents who assessed their oral health as good and those who assessed their oral health as poor. Number of carious and missing teeth remained linked to the assessment of oral health after regression analysis was applied. People with lower number of carious and missing teeth assessed their oral health as good. Significant association between the number of untreated and missing teeth was recorded after inclusion of socio-demographic factors in the analysis, and specially those who have demonstrated significant impact on self-assessment in bivariate analysis. Our results are consistent with other studies which showed that likelihood of oral health assessed as poor increases with increased number of carious and missing teeth $[5,7,10]$. Possible reasons for strong association between the number of carious and missing teeth and assessment of oral health are unsatisfying appearance of mouth and teeth, reduced chewing efficiency, and need for prosthetic treatment. Higher number of restored tooth is associated with good oral health perception $[5,7]$, but this association was not found in the current study after inclusion of all factors in regression analysis.

Oral health perception has been associated with use of health care services and objective clinical indicators of oral health [22]. If people assess their oral health as poor or there is a specific oral problem, their health behavior can change (visits to dentist, oral hygiene), as well as oral status. Therefore, self-assessment of oral health can provide important information that will lead not only to improved promotion of oral health, but also improved health care.

Table 3. Non-adjusted and adjusted regression analysis for self assessment of oral health

Tabela 3. Neprilagođena i prilagođena regresiona analiza za samoprocenu oralnog zdravlja

\begin{tabular}{|l|c|c|c|c|c|c|c|c|}
\hline \multirow{2}{*}{$\begin{array}{l}\text { Teeth } \\
\text { Zubi }\end{array}$} & \multicolumn{4}{|c|}{$\begin{array}{c}\text { Non-adjusted regression analysis } \\
\text { Neprilagođena regresiona analiza }\end{array}$} & \multicolumn{4}{c|}{$\begin{array}{c}\text { Adjusted regression analysis } \\
\text { Prilagođena regresiona analiza }\end{array}$} \\
\cline { 2 - 9 } & B & SE & $(95 \% \mathrm{Cl})$ & $\mathbf{p}$ & $\mathbf{B}^{*}$ & SE* $^{*}$ & $(95 \% \mathrm{Cl})^{*}$ & $\mathbf{p}^{*}$ \\
\hline $\begin{array}{l}\text { Carious } \\
\text { Karijesni }\end{array}$ & 0.424 & 0.120 & $1.208-1.933$ & $<0.0001$ & 0.454 & 0.140 & $1.198-2.071$ & 0.001 \\
\hline $\begin{array}{l}\text { Extracted } \\
\text { Ekstrahovani }\end{array}$ & 0.394 & 0.087 & $1.250-1.759$ & $<0.0001$ & 0.460 & 0.118 & $1.257-1.997$ & $<0.0001$ \\
\hline $\begin{array}{l}\text { Filled } \\
\text { Plombirani }\end{array}$ & -0.058 & 0.062 & $0.835-1.066$ & 0.352 & -0.057 & 0.073 & $0.818-1.091$ & 0.438 \\
\hline
\end{tabular}

* adjusted for gender, age, educational level and smoking habit

$\mathrm{B}$ - regression coefficient; $\mathrm{SE}$ - standard error; $\mathrm{Cl}$ - confidence interval

* prilagođeno za pol, starosnu dob, stepen obrazovanja i naviku pušenja

$\mathrm{B}$ - regresioni koeficijent; $\mathrm{SE}$ - standardna greška; $\mathrm{Cl}$ - interval poverenja 


\section{CONCLUSION}

Number of carious and missing teeth significantly affected self-perception of oral health. Knowledge of the effects of oral clinical variables on the self-perception of oral health is of great importance to get clearer view about association between objectively and subjectively assessed oral health.

\section{REFERENCES}

1. Peres KG, Peres MA, Araujo CL, Menezes AM, Hallal PC. Social and dental status along the life course and oral health impacts in adolescents: a population-based birth cohort. Health Qual Life Outcomes. 2009; 7:95. [DOI: 10.1186/1477-7525-7-95] [PMID:19930601]

2. Kida IA, Astrom AN, Strand GV, Masalu JR, Tsakos G. Psychometric properties and the prevalence, intensity and causes of oral impacts on daily performance (OIDP) in a population of older Tanzanians. Health Quality Life Outcomes. 2006; 4:56. [DOI: 10.1186/1477-7525-4-56] [PMID: 16934161]

3. Samorodnitzky GR, Levin L. Self-assessed dental status, oral behavior, DMF, and dental anxiety. J Dent Educ. 2005; 69:1385-9. [PMID: 16352775]

4. Pattussi MP, Peres KG, Boing AF, Peres MA, da Costa JS. Self-rated oral health and associated factors in Brazilian elders. Community Dent Oral Epidemiol. 2010; 38:348-59.

[DOI: 10.1111/j.1600-0528.2010.00542.x] [PMID: 20406272]

5. Wu B, Plassman BL, Liang J, Remle RC, Bai L, Crout RJ. Differences in self-reported oral health among community-dwelling black, Hispanic, and white elders. J Aging Health. 2011; 23:267-88. [DOI: 10.1177/0898264310382135] [PMID: 20858912]

6. Kaplan G, Baron-Epel O. What lies behind the subjective evaluation of health status? Soc Sci Med. 2003; 56:1669-76.

[DOI: 10.1016/S0277-9536(02)00179-X] [PMID: 12639584]

7. Locker D, Mscn EW, Jokovic A. What do older adults' global selfratings of oral health measure? J Public Health Dent. 2005; 65:146-52. [DOl: 10.1111/j.1752-7325.2005.tb02804.x] [PMID: 16171259]

8. Andrade FB, Lebrao ML, Santos JL, Duarte YA, Teixeira DS. Factors related to poor self-perceived oral health among community-dwelling elderly individuals in Sao Paulo, Brazil. Cad Saude Publica. 2012; 28:1965-75. [DOI: 10.1590/S0102-311X2012001000014] [PMID: 23090175]

9. Northridge ME, Chakraborty B, Kunzel C, MetcalfS, Marshall S, Lamster IB. What contributes to self-rated oral health among community-dwelling older adults? Findings from the ElderSmile program. J Public Health Dent. 2012; 72:235-45.

[DOI: 10.1111/j.1752-7325.2012.00313.x] [PMID: 22316102]
10. Thomson WM, Mejia GC, Broadbent JM, Poulton R. Construct validity of Locker's global oral health item. J Dent Res. 2012; 91:1038-42. [DOI: 10.1177/0022034512460676] [PMID: 22983410]

11. Kojima A, Ekuni D, Mizutani S, Furuta M, Irie K, Azuma T, et al. Relationships between self-rated oral health, subjective symptoms, oral health behavior and clinical conditions in Japanese university students: a cross-sectional survey at Okayama University. BMC Oral Health. 2013; 13:62. [DOI: 10.1186/1472-6831-13-62] [PMID: 24195632]

12. Nunes $\mathrm{Cl}$, Abegg $\mathrm{C}$. Factors associated with oral health perception in older Brazilians. Gerodontology. 2008; 25:42-8. [DOI: 10.1111/j.1741-2358.2007.00163.x] [PMID: 18289131]

13. Ministarstvo zdravlja Republike Srbije. Istraživanje zdravlja stanovnika Republike Srbije 2013. godine. Available from: http://zdravlje.gov.rs/. [cited 29 Aug 2015]

14. World Health Organisation. Oral Health Surveys. Basic methods. Geneva: WHO; 1997.

15. Mashoto KO, Astrom AN, Skeie MS, Masalu JR. Socio-demographic disparity in oral health among the poor: a cross sectional study of early adolescents in Kilwa district, Tanzania. BMC Oral Health. 2010; 10:7. [DOI: 10.1186/1472-6831-10-7] [PMID: 20406452]

16. Petersen PE. Sociobehavioural risk factors in dental caries - international perspectives. Community Dent Oral Epidemiol. 2005; 33:274-9. [DOl: 10.1111/j.1600-0528.2005.00235.x] [PMID: 16008634]

17. Locker D. Self-esteem and socioeconomic disparities in self-perceived oral health. J Public Health Dent. 2009; 69:1-8. [DOI: 10.1111/j.1752-7325.2008.00087.x] [PMID: 18662257]

18. Turrell G, Sanders AE, Slade GD, Spencer AJ, Marcenes W. The independent contribution of neighborhood disadvantage and individual-level socioeconomic position to self-reported oral health: a multilevel analysis. Community Dent Oral Epidemiol. 2007; 35:195206. [DOl: 10.1111/j.1600-0528.2006.00311.x] [PMID: 17518966]

19. Naghibi Sistani MM, Yazdani R, Virtanen J, Pakdaman A, Murtomaa H. Determinants of oral health: does oral health literacy matter? ISRN Dent. 2013; 2013:6. [DOI: 10.1155/2013/249591] [PMID: 23577262]

20. Gabardo MC, Moysés SJ, Moysés ST, Olandoski M, Olinto MT, Pattussi MP. Multilevel analysis of self-perception in oral health and associated factors in Southern Brazilian adults: a cross-sectional study.Cad Saude Publica. 2015; 31:49-59. [DOI: 10.1590/0102-311X00037814] [PMID: 25715291]

21. Rooban T, Vidya K, Joshua E, Rao A, Ranganathan S, Rao UK, et al. Tooth decay in alcohol and tobacco abusers. J Oral Maxillofac Pathol. 2011; 15:14-21. [DOI: 10.4103/0973-029X.80032] [PMID: 21731272]

22. Gift HC, Atchison KA, Drury TF. Perceptions of the natural dentition in the context of multiple variables. J Dent Res. 1998; 77:1529-38. [DOI: 10.1177/00220345980770070801] [PMID: 9663438] 


\title{
Uticaj oralnih kliničkih faktora na samoprocenu zdravlja usta i zuba
}

\author{
Dajana Nogo-Živanović, Ljiljana Kulić, Aleksandra Žuža, Brankica Davidović, Igor Radović \\ Univerzitet u Istočnom Sarajevu, Medicinski fakultet, Katedra za bolesti zuba i endodonciju, Foča, Republika Srpska, \\ Bosna i Hercegovina
}

\begin{abstract}
KRATAK SADRŽAJ
Uvod Procena sopstvenog oralnog zdravlja je jednostavan, neinvazivan i ekonomičan način prikupljanja podataka koji uzima u obzir i psihosocijalne aspekte zdravlja usta i zuba. Cilj ovog rada je bio da se utvrdi uticaj kliničkih faktora na samoprocenu stanja oralnog zdravlja osoba srednje životne dobi među stanovnicima Republike Srpske (Bosna i Hercegovina).

Materijal i metode rada Uzorak je činilo 126 ispitanika oba pola (34,1\% muškaraca i 65,9\% žena) starosti 24-54 godine. Podaci su prikupljeni na osnovu upitnika i kliničkog pregleda. Anonimni upitnik je sadržao pitanja u vezi sa sociodemografskim odlikama ispitanika. Klinički pregled je obuhvatio procenu stanja zuba i zastupljenost protetičkih nadoknada. Samoprocena oralnog zdravlja je određena na osnovu jednog pitanja.

Rezultati Bivarijantna analiza je ukazala na statistički značajan uticaj broja karijesnih $(p<0,001)$, ekstrahovanih $(p<0,001)$ i saniranih $(p=0,022)$ zuba, ali ne i protetičkog stanja na procenu oralnog zdravlja. Povezanost broja karijesnih i zuba koji nedostaju sa samoprocenom oralnog zdravlja je ostala statistički značajna i u regresionoj analizi.

Zaključak Broj karijesnih i zuba koji nedostaju značajno utiče na samoprocenu zdravlja usta i zuba u ispitivanoj populaciji. Poznavanje uticaja oralnih kliničkih varijabli na samoprocenu oralnog zdravlja je od velikog značaja, da bi se dobio jasniji uvid o povezanosti objektivnog i subjektivno procenjenog oralnog zdravlja.

Ključne reči: procena oralnog zdravlja; karijes; socioekonomski faktori
\end{abstract}

\section{UVOD}

Za procenu zdravlja usta i zuba pojedinaca u kliničkim i epidemiološkim istraživanjima najčešće se koriste objektivni klinički pokazatelji [1]. Ovakav način procene oralnog zdravlja, pored niza prednosti, ima i svoje nedostatke, jer u obzir ne uzima psihosocijalne aspekte oralnog zdravlja i individualnu percepciju oralnog zdravlja [2]. U istraživanjima o zdravlju usta i zuba korisni podaci se mogu dobiti na osnovu individualne procene oralnog zdravlja [3]. Ova metoda, pored toga što je jednostavna za primenu, ekonomski je prihvatljiviji način prikupljanja podataka o oralnom zdravlju populacije u odnosu na klinička ispitivanja $[4,5,6]$. U poslednje vreme samoprocena zdravlja usta i zuba vrši se na osnovu jednog pitanja [6].

U brojnim istraživanjima uočena je povezanost samoprocene oralnog zdravlja, određene na osnovu jednog pitanja, i brojnih kliničkih pokazatelja zdravlja usta i zuba $[4,7,8,9,10]$. Osobe s većim brojem karijesnih i ekstrahovanih zuba najčešće procenjuju svoje oralno zdravlje kao loše $[5,7,10]$, dok oni s većim brojem saniranih zuba smatraju da je njihovo oralno zdravlje dobro $[5,7]$. Oralno zdravlje procenjeno kao loše povezuje se i s visokim vrednostima indeksa KEP, malokluzijom, zuboboljom i bolom temporomandibularnog zgloba, protetičkim statusom i potrebama za stomatološkim lečenjem $[5,7,11,12]$.

$\mathrm{U}$ istraživanju zdravlja stanovnika u regionu (Republika Srbija) navodi se da skoro polovina odraslog stanovništva $(45,5 \%)$ procenjuje stanje svojih zuba i usne duplje kao dobro ili veoma dobro [13]. Takođe, rezultati ukazuju da je procena oralnog zdravlja povezana s ukupnim prihodima domaćinstva, stepenom obrazovanja, polom i područjem u kojem ispitanici žive [13].

Cilj ovog rada je bio da se utvrdi uticaj kliničkih faktora na procenu stanja oralnog zdravlja osoba srednje životne dobi koji žive na teritoriji Republike Srpske (Bosna i Hercegovina).

\section{MATERIJAL I METODE RADA}

Studija preseka izvedena je od januara do jula 2013. godine na Odeljenju za bolesti zuba i endodonciju Medicinskog fakulteta u Foči, Univerziteta u Istočnom Sarajevu, u Republici Srpskoj (RS). Uzorak je činilo 126 ispitanika oba pola (34,1\% muškaraca i $65,9 \%$ žena) starosti od 24 do 54 godine (prosečna starost bila je 32,36 $\pm 5,93$ godine). Ciljna populacija odabrana je metodom slučajnog izbora od osoba koje su se prvi put javile na Odeljenje za bolesti zuba i endodonciju Medicinskog fakulteta u Foči. Nakon upoznavanja s ciljevima i očekivanim ishodima studije, svi ispitanici su potpisali pristanak za učešće u istraživanju.

Podaci su prikupljeni na osnovu upitnika i kliničkog pregleda. Anonimni upitnik je sadržao pitanja u vezi sa sociodemografskim odlikama ispitanika: starost, pol, stepen obrazovanja (završena osnovna škola, srednja škola ili viša škola, završen fakultet i više), zaposlenje (zaposlen s punim ili nepunim radnim vremenom, nezaposlen), ukupan mesečni prihod svih članova domaćinstva (manje od jedne prosečne plate $u$ RS, 1-2 prosečne plate u RS, 2-3 prosečne plate $u$ RS, više od četiri prosečne plate u RS - u periodu kada je rađeno istraživanje), navika pušenja u poslednjih godinu dana (da, ne) i vreme proteklo od poslednje posete stomatologu (poseta u poslednjih šest meseci, 6-12 meseci, 1-2 godine i više od dve godine). Ispitivane varijable su radi statističke analize dihotomizirane. Stepen obrazovanja je klasifikovan u dve kategorije: završena osnovna i/ili srednja škola i završena viša škola, fakultet i više; zaposlenje na: zaposlen i nezaposlen; ukupan prihod svih članova domaćinstva: do dve prosečne plate u RS i prihod veći od dve prosečne plate. Poseta stomatologu u poslednjih 12 meseci je dihotomizirana na posetu u okviru 12 meseci i posetu od koje je prošlo više od 12 meseci.

Procena oralnog zdravlja utvrđena je na osnovu pitanja: „Kako biste ocenili zdravlje vaših zuba?“, a ponuđeni odgovori 
su bili: „,Odlično“, „Veoma dobro“, „Dobro“, „Prosečno“, „Loše“ i „Veoma loše“. Zbog regresione analize, varijabla je dihotomizirana, tako da su odgovori „Odlično“, „Veoma dobro“, „Dobro“ i „Prosečno“ svrstani u jednu kategoriju (Dobro), a odgovori „Loše“ i „Veoma loše“ u drugu (Loše).

Klinički pregled je obuhvatio procenu stanja zuba i zastupljenost protetičkih nadoknada, a obavio ga je obučeni stomatolog na Odeljenju za bolesti zuba i endodonciju Medicinskog fakulteta u Foči uz primenu veštačkog osvetljenja, stomatološkog ogledalceta i sonde prema standardima i kriterijumima Svetske zdravstvene organizacije [14]. Rasprostranjenost karijesa određena je pomoću indeksa KEP i njegovih komponenti ( $\mathrm{K}$ - karijesni zub, E - ekstrahovan zub, P - plombiran zub). Vrednost unutar istraživačke saglasnosti, merena koeficijentom kapa ( $\mathrm{\kappa})$, bila je 0,85 . Analiza je obuhvatila i treće molare, a prilikom pregleda ispitivana je svaka površina zuba. Procena protetičkog stanja gornje i donje vilice izvršena je na osnovu postojanja ili izostanka bilo koje vrste protetičke nadoknade, pa su ispitanici svrstani u dve grupe: ispitanici koji imaju bar jednu protetičku nadoknadu (parcijalna proteza i/ili totalna proteza i/ili fiksna nadoknada) i oni koji je nemaju.

\section{Statistička analiza}

Statistička analiza je urađena u statističkom programu SPSS, verzija 19.0 (IBM SPSS Statistics for Windows, Armonk, NY: IBM Corp, USA) za Windows. Podaci su prikazani u obliku srednjih vrednosti i standardnih devijacija za numerička obeležja i učestalosti za atributivna obeležja. Razlike u samoproceni oralnog zdravlja u zavisnosti od ispitivanih varijabli su u bivarijantnoj analizi određene primenom Studentovog t-testa za dva nezavisna uzorka i $\chi^{2}$-testa. Primenom logističke regresije ispitana je povezanost oralnih kliničkih varijabli i samoprocene zdravlja usta i zuba. Oralno zdravlje procenjeno kao dobro je izabrano za referentnu kategoriju. Vrednosti $\mathrm{p}<0,05$ smatrane su statistički značajnim u svim analizama.

\section{REZULTATI}

Sociodemografske odlike ispitanika i navike prikazane su u tabeli 1. Bivarijantna analiza je pokazala da su starosna dob $(p=0,019)$, stepen obrazovanja $(p<0,0001)$ i pušenje $(p \leq 0,0001)$ sociodemografski faktori i navike koji su značajno povezani s procenom oralnog zdravlja (Tabela 1). Od ispitivanih oralnih klinički varijabli, broj karijesnih, ekstrahovanih i saniranih zuba, ali ne i protetički status, značajno se razlikuje između ispitanika koji su svoje oralno zdravlje procenili kao dobro i onih koji su oralno zdravlje procenili kao loše (Tabela 2).

Nakon logističke regresione analize varijable koje su ostale povezane s procenom oralnog zdravlja su broj karijesnih $(\mathrm{p} \leq 0,0001)$ i ekstrahovanih zuba $(\mathrm{p} \leq 0,0001)$. Osobe $s$ manjim brojem karijesnih i ekstrahovanih zuba svoje oralno zdravlje procenile su kao dobro (Tabela 3). Povezanost broja karijesnih i zuba koji nedostaju sa samoprocenom oralnog zdravlja ostala je statistički značajna i posle prilagođavanja za pol, starosnu dob, stepen obrazovanja i naviku pušenja.

\section{DISKUSIJA}

Ova studija pokazuje uticaj broja nesaniranih i zuba koji nedostaju na procenu oralnog zdravlja. Uticaj sociodemografskih faktora na procenu zdravlja usta i zuba indirektno je povezan s faktorima sredine, psihosocijalnim faktorima, načinom života i dostupnosti usluga stomatološke zdravstvene zaštite [15]. Osim toga, sociodemografski faktori mogu direktno ili indirektno uticati na odnos pojedinca ka oralnom zdravlju $[15,16]$. Ukupni prihodi domaćinstva imaju veliki uticaj na procenu oralnog zdravlja [17], a ispitanici s manjim ukupnim prihodima mnogo češće svoje zdravlje ocenjuju kao loše $[17,18]$. Takođe, starost, niži socioekonomski status i niži stepen obrazovanja povezuju se s lošijom procenom oralnog zdravlja [19]. Slični nalazi su dobijeni i u ovom istraživanju. Od ispitivanih sociodemografskih obeležja ispitanika, značajna povezanost je uočena između starosne dobi, stepena obrazovanja, pušenja i procene oralnog zdravlja. Navika pušenja može uticati na procenu zdravlja usta i zuba [20], jer postoje nalazi kojima se pušenje dovodi u vezu s nastankom karijesa [21].

Analizom pojedinačnih komponenata indeksa KEP u ovom istraživanju uočena je statistički značajna razlika u broju karijesnih, ekstrahovanih i saniranih zuba između ispitanika koji su svoje oralno zdravlje procenili kao dobro u odnosu na one koji su oralno zdravlje procenili kao loše. Broj karijesnih i ekstrahovanih zuba je ostao povezan s procenom oralnog zdravlja i nakon regresione analize. Osobe sa manjim brojem karijesnih i ekstrahovanih zuba oralno zdravlje su procenile kao dobro. Značajna povezanost broja nesaniranih i zuba koji nedostaju je zabeležena i posle uključivanja sociodemografskih faktora u analizu, i to onih koji su pokazali statistički značajan uticaj na samoprocenu u bivarijantnoj analizi. Ovi rezultati su u skladu $s$ nalazima drugih studija gde se verovatnoća da se oralno zdravlje proceni kao loše uvećava s povećanjem broja karijesnih i ekstrahovanih zuba $[5,7,10]$. Mogući razlozi povezanosti broja karijesnih i ekstrahovanih zuba i procene oralnog zdravlja mogu biti nezadovoljstvo izgledom usta i zuba, smanjenje žvačne efikasnosti, kao i potreba za protetičkim lečenjem. Veći broj saniranih zuba se dovodi u vezu s procenom oralnog zdravlja $[5,7]$, ali ta povezanost nije nađena u ovom istraživanju posle uključivanja svih faktora u regresionu analizu.

Procena oralnog zdravlja je povezana s korišćenjem usluga zdravstvene zaštite i stvarnim kliničkim pokazateljima oralnog zdravlja [22]. Ukoliko ljudi zdravlje svojih usta i zuba procenjuju kao loše ili ukoliko postoji određeni oralni problem, kao rezultat može doći do promena u zdravstvenom ponašanju pojedinca (poseta stomatologu, održavanje oralne higijene), ali i do promena u njihovom oralnom stanju. Stoga, samoprocena oralnog zdravlja može pružiti važne informacije koje će dovesti ne samo do poboljšanja promocije oralnog zdravlja, već i unapređenja zdravstvene zaštite.

\section{ZAKLJUČAK}

Broj karijesnih i zuba koji nedostaju značajno utiče na samoprocenu oralnog zdravlja u ispitivanoj populaciji. Poznavanje uticaja oralnih klinički varijabli na samoprocenu oralnog zdravlja od velikog je značaja radi dobijanja jasnijeg uvida o povezanosti objektivnog sa subjektivno procenjenim zdravljem usta i zuba. 